\title{
Inventividade e desvio na série Ad Vitam:
}

\section{As vicissitudes humanas em contexto distópico}

\section{Inventiveness and deviation in the Ad Vitam series: \\ Human vicissitudes in a dystopian context}

\section{Breno da Silva Carvalho}

Doutor em Antropologia pela UFBA e Professor do Departamento de Comunicação da UFRN. Universidade Federal do Rio Grande do Norte, Departamento de Comunicação, Natal (RN), Brasil.

\section{Raquel Assunção Oliveira}

Mestre em Comunicação pela UFRN e Professora do Departamento de Comunicação da UFRN. Universidade Federal do Rio Grande do Norte, Departamento de Comunicação, Natal (RN), Brasil.

\section{Introdução: as premissas narrativas de Ad Vitam}

Em Ad Vitam (2018), do latim "para a vida", vivencia-se um tempo futuro após evento pandêmico iniciado na América do Norte. Sobreviver e manter-se vivo são as conquistas mais significativas para a humanidade. Adoecer e envelhecer são possíveis de retardamento, e a solução deriva do processo de regeneração celular realizado corriqueiramente na sociedade, quando reconhecida a compatibilidade genética assegurada a partir da maioridade - na obra, 30 anos.

A partir dos eixos de mortalidade e suicídio, estrutura-se o argumento dessa série francesa, criada por Sébastien Mounier, com direção de Thomas Cailley e Manuel Schapira. Lançada em 2018 no canal 
europeu Arte, a produção está disponível em sua totalidade na Netflix, plataforma de streaming, desde 2019 - uma única temporada de seis episódios, cada um deles com média de 50 minutos de duração.

Na série, a recuperação física e motora dos indivíduos inspira-se na água-viva (espécie Turinapsis idraecula), tomada como símbolo da eterna juventude e da imortalidade - o primeiro episódio, por exemplo, retrata a comemoração do aniversário de 169 anos da mulher mais velha do mundo.

Apesar dos avanços médicos e científicos, inexiste um consenso entre os atores sociais sobre sua permanência no mundo ao longo de inúmeros anos: grupos sociais tentam vivenciar o envelhecimento em sua temporalidade biológica, e alguns jovens recorrem ao suicídio como uma resposta radical a partir da obrigatoriedade de manter-se "para a vida".

É nesse contexto que se deflagra a investigação sobre a morte de sete adolescentes encontrados à beira-mar: seria uma nova situação de suicídio coletivo, como o realizado há 10 anos em um estádio esportivo? Para a resolução do enigma policial, o espectador é convidado a acompanhar a jornada de investigação de Darius Asram (interpretado por Yvan Attal), policial de 120 anos, com Christa Novak (interpretada por Garance Marillier), jovem de 24 anos - logo, menor de idade -, sobrevivente do episódio de uma década atrás, convocada pelo profissional como peça-chave para a situação.

O parâmetro metodológico para a reflexão sobre a narrativa recorre a Penafria (2009). Com base na autora, articulam-se os seguintes referenciais: (a) análise interna à obra: reconhecimento de sua singularidade; (b) análise de conteúdo: compreensão da série como um relato com tema específico.

Tal definição analítica permite a identificação de premissas que enredam a narrativa, como a discussão sobre a perpetuidade da vida e a percepção acerca das motivações subjetivas individuais, as quais serão discutidas na seção seguinte com o auxílio de referenciais socioantropológicos e comunicacionais contemporâneos.

\section{A singularidade de Ad Vitam e sua originalidade temática}

Narrativas fílmicas e seriais com abordagem distópica evocam significativos debates para a modernidade ocidental ao insurgirem-se sobre o imaginário social, emulando futuros ficcionais próximos ou distantes. Obras como Metrópolis (1927), Blade Runner (1982), Gattaca (1997), Matrix (1999), Guerra 


\section{ALCEU}

ISSN: $2175-7402$

dos Mundos (2005), Ensaio sobre a cegueira (2008), Melancolia (2011), Contágio (2011) ${ }^{1}$ e Branco sai, preto fica (2015) propõem-se a investigar os desígnios da humanidade a partir da projeção desses cenários. Por distopia, alinhamo-nos à posição de Almeida (2018, p. 5), quando a compreende em contraposição à utopia. Para o pesquisador:

Utopia é sonho; distopia, pesadelo. [...] Utopia e distopia são como os lados de uma mesma moeda, que estampa tanto o projeto moderno de uma sociedade mais justa, organizada em benefício do desenvolvimento coletivo e da felicidade individual, quanto o pesadelo de um mundo caótico, afetado por uma guerra nuclear, pela escassez dos recursos naturais ou pelos efeitos do terrorismo.

A série, no entanto, tem a particularidade de mesclar elementos recorrentes nas narrativas distópicas com características clássicas do gênero policial, aqui entendido dentro de uma categoria ainda mais ampla, que é a do thriller (ALMEIDA, 2007), este último caracterizado por contemplar os seguintes elementos: "uma relação dialética com o presente histórico da sociedade em que nasce (relação tomada, às vezes, em sentido metafórico); uma raiz expressionista, presente nas tonalidades atmosféricas de sua estética; a ambiguidade na produção de sentido dentro desses filmes." (p. 139).

A exploração do gênero policial é uma propriedade relevante de ser mencionada nesta reflexão acerca de $A d$ Vitam, sobretudo devido ao protagonismo que o personagem Darius - um policial - tem na trama. Ainda em diálogo com Marco Antônio de Almeida (2002), a narrativa policial, de modo mais amplo, tem seu nascedouro nas literaturas francesa e anglo-saxã do século XIX. Vale acrescentar: também dentro de um contexto social disciplinar (FOUCAULT, 2014). Seu surgimento é indissociável e reforça, portanto, "o paradigma iluminista da Razão, ao mostrar como o raciocínio dedutivo é capaz de esclarecer mistérios" (ALMEIDA, 2002, p. 82).

Nesse movimento, o conhecimento científico tem um papel central, legitimando ou destinando às margens as estratégias de saber - e, consequentemente, de poder - inscritas sobre os corpos (FOUCAULT, 2021). A narrativa da série descortina todo um processo investigativo que é indissociável das técnicas de saber/poder, estas validadas pelas descobertas médico-científicas do universo fílmico, que serão comentadas nas próximas seções. Acerca dos fatores que contribuíram para o espalhamento das narrativas policiais, estão:

\footnotetext{
${ }^{1}$ Em janeiro de 2020, com o reconhecimento da pandemia do COVID-19, o filme, dirigido por Steven Soderbergh, alcançou a décima posição no ranking de locação de filmes do iTunes (GARDNER; MCCLINTOCK, 2020).
} 
o raciocínio lógico-dedutivo; a criação de um aparelho policial com bases científicas por parte do Estado; a metrópole e a problemática urbana como pano de fundo (as massas, a pobreza, a delinquência); a ambientação do crime e sua solução como centro da intriga; a emergência do indivíduo e a problemática da constituição das identidades (ALMEIDA, 2002, p. 82).

A abordagem construída pela trama de Ad Vitam garante sua singularidade na perspectiva da análise interna da obra (PENAFRIA, 2009). Em seus seis episódios, a composição narrativa possibilita o manejo de temas atuais, correlacionando problemáticas dos domínios da comunicação, demografia, direito, sociologia e antropologia. Convém destacar, por exemplo, o relato dado no primeiro episódio pelo personagem Markus Larcher, sociólogo e consultor sobre juventude, ao conceder entrevista a um canal de televisão:

Se não envelhecemos mais, se não morremos mais, como vamos abrir espaços para as novas gerações? Porque são elas que pagam o alto preço dos nossos sonhos. [...] Esses movimentos radicais nasceram dessa falta de perspectiva [...] [O referendo sobre controle de natalidade?] Sim! Eu sempre converso com os jovens e eles me dizem que se sentem pessoalmente atacados pelo referendo. Eles sentem que estamos tentando nos livrar deles. [...] Não pensem que quero justificar a violência cometida por eles, mas notei que esse ato [de sucídio coletivo] é profundamente político. [...] Nos últimos 60 anos, a vida se tornou o valor absoluto de nossa civilização. Esses suicídios coletivos forçam nossa sociedade a encarar a possibilidade da morte e 0 desejo pela morte. Nada é eterno. (AD VITAM, 2018).

A fala explicita categorias centrais da série, como envelhecimento, morte, formação de novas gerações, valorização da vida para o sujeito etc. Isso suscita, por exemplo, o enfrentamento de questões ligadas ao controle de natalidade, crescimento populacional, maioridade e agências individuais.

O relato (PENAFRIA, 2009) de $A d$ Vitam resulta de um processo criativo em que o binômio vida e morte move a narrativa, firmando-se como seu tema central. A partir dele derivam e se articulam conteúdos originais acerca das seguintes categorias: (a) saúde e desempenho; (b) tempo, articulado à noção de mentalidade; e, por fim, (c) formulação de projetos de vida e comportamentos desviantes noções estas que serão discutidas na próxima seção.

\section{Ad aeternum: viver é permanecer?}

Em relação à linguagem audiovisual apresentada, Ad Vitam maneja algumas particularidades. A composição visual e a sonoridade da série resultam na criação de um universo distópico amparado na pósmodernidade (HAN, 2017; 2018). A narrativa enxuta, precisa e sintética - principalmente quando 
comparada a outras produções tradicionais, hábeis em emular a representação cinematográfica de blockbusters - resulta em uma trama que se desenvolve com ritmo lento e contido.

A fotografia é assinada por Yves Cape - profissional que já trabalhou com importantes cineastas contemporâneos, como Bruno Dumont e Leos Carax - e privilegia tons frios e luminosidade neon, com ênfase no azul, presente em diversos elementos: mar, água-viva, iluminação urbana, roupas e demais elementos cênicos. O conjunto visual combina-se com a trilha sonora eletrônica criada pelo coletivo parisiense HiTnRuN, conferindo um "sentido moderno, extremamente ritmado e [que] casa na perfeição com a direção de fotografia" (ROSA, 2018).

Em relação à narrativa, Ad Vitam move-se, ironicamente, a partir de mortes - apesar de a sociedade celebrar a vitalidade por meio da recuperação física/biológica. Apura-se o surgimento de corpos de jovens em uma praia como uma provável nova ação da SAUL, célula pró-suicídio, responsável pelo movimento contra a regeneração e pela ocorrência pregressa do episódio de suicídio coletivo no estádio esportivo com 23 mortos. Tais fatos geram dores e apontam a formação de lacunas - sociais e existenciais -, seja no coletivo ou em indivíduos.

A protagonista da trama, Christa Novak, sofre uma dor emancipatória: seu sofrimento pode levá-la à morte ou a um quadro de desequilíbrio psíquico - felizmente, ao final da narrativa, possibilidades mais positivas e esperançosas são lançadas. Porém, é exatamente na expressão das dores que a personagem se humaniza. Em contraponto ao perfil da jovem, há o de Darius Asram: o policial regenerado, imerso em dores pessoais, como a perda do filho.

O avanço da narrativa acompanha as tensões dessa relação e as motivações subjetivas das personagens: há uma oposição entre a recusa à imortalidade da jovem e a expectativa de vitalidade permanente por parte de Darius. Em entrevista, Cailley (2018, tradução nossa), um dos diretores da série, enfatiza essas divergências e destaca as questões existenciais que a narrativa evoca:

No plano pessoal, o que me tocou foi o que acontece com uma sociedade em que se pode prolongar a vida indefinidamente, em que não se morre mais. O que resta para ser transmitido quando não morrermos mais? E se não nos aposentarmos mais? Se não temos capital, nem conhecimento, nem cultura para ceder a alguém, se guardamos tudo para nós, qual é, em última análise, o interesse ontológico para o homem? Então começamos com essa questão um tanto filosófica e tentamos tratá-la na forma, ao mesmo tempo, de uma história de detetive, e especialmente de uma intriga relacional entre um homem de 120 anos que vive plenamente sua imortalidade e uma jovem mulher que está na casa dos vinte e não vê o sentido da vida em tudo. Para ver como isso flui entre essas duas pessoas e como cada uma tem coisas para transmitir. 
Olhar para essa convivência é lançar luz ao entendimento sobre valores culturais correntes e sua dinâmica de transmissibilidade às novas gerações. Para tanto, serão discutidas questões ligadas à saúde, tempo e projeto de vida.

\subsection{A positividade em Ad Vitam}

No universo diegético de Ad Vitam, a saúde é celebrada e mantida, periodicamente, com a realização de procedimentos de regeneração pelos maiores de idade - quando geneticamente compatíveis. A prática consiste em uma imersão em tanques, espécies de câmaras de bronzeamento artificial, disponíveis em locais especializados - semelhantes às contemporâneas clínicas estéticas - e espalhadas por todo o país.

Em um cenário com tamanha pujança de vitalidade e valorização da saúde, emergem experiências que tangenciam a morte: pílulas que emulam a sensação de óbito; galpões para a prática de luta livre (também equipados com máquinas de regeneração para os participantes); sex shops - ou melhor, Death Shops - com aparelhos e utensílios que propiciam a "quase-morte": garrotes para asfixia (com controle remoto e trava de segurança) e veneno de animais peçonhentos (acompanhados dos respectivos antídotos).

Ainda nessa loja, é exibido um espelho com a seguinte sinalização: "veja seu reflexo de verdade". Nele, os curiosos podem saciar seu desejo de verem-se com a fisionomia que realmente teriam com a idade "atual": o envelhecimento é projetivo, mas não se cumpre como práxis social efetiva.

A construção social desses dispositivos/soluções para a mínima vivência e aproximação da velhice e da morte é estratégica para a legitimação da imprescindibilidade da vida. Afinal, como sugere Byung-Chul Han (2018, p. 47), "uma vida que fosse constituída unicamente de emoções positivas e experiências máximas não seria humana. É precisamente à negatividade a que o espírito humano deve sua profunda tensão".

Se a morte estaria alocada no polo negativo, sua anulação coloca em suspensão essa possibilidade e projeta o exercício vital em fluxo contínuo e ininterrupto. Neste sentido, Han $(2018$, p. 108) aponta o 
novo posicionamento concedido à saúde: "[ela] é elevada à nova deusa e deve ser prolongada a qualquer custo e com todos os meios".

Consequentemente, desdobram-se duas questões interligadas: (1) surge um "sujeito do desempenho", um "empresário de si mesmo", a verdadeira materialização dos discursos de motivação individuais que se multiplicam na atualidade; além dos (2) efeitos colaterais desse processo, como sofrimento psíquico e transtornos mentais - por exemplo, depressão, Transtorno do Déficit de Atenção com Hiperatividade (TDAH), Síndrome de Burnout, dentre outras.

Na condição de "explorador e ao mesmo tempo explorado" (HAN, 2017, p. 105), o sujeito do desempenho é fruto do atual cenário econômico neoliberal em que a maximização dos lucros firma protagonismo e relevância. Essa conjuntura delineia um sistema que encontra na autoexploração do sujeito uma estratégia extremamente eficaz para o aumento da produtividade - realização que "é muito mais eficiente que a exploração estranha, pois caminha de mãos dadas com o sentimento de liberdade" ( $p$. 115) e, consequentemente, de autonomia, de ser "dono" do seu próprio tempo, ser seu próprio "chefe".

Diante do cenário contemporâneo, Han $(2017,2018)$ afirma que se vivencia uma época "neuronal", baseada no excesso de positividade. Um momento em que a violência não pode mais ser justificada pela existência de uma alteridade a ser combatida - seja ela correspondente a células terroristas, vírus biológicos ou de computador etc. -, posto que é decorrente de um "excesso de igual". Trata-se, portanto, de uma violência entranhada no sistema, derivada de uma sociedade do desempenho.

Se a atuação de Darius visa a manutenção da produtividade, o propósito de Christa é traçar novos referenciais de performance, ancorados na ruptura e na possibilidade de lançar-se em busca de outras alternativas, como sugere a sequência que encerra a série. Ao mar, ela assume sua legítima postura de refugiada impulsionada pela liberdade e interessada em romper aprisionamentos biológicos (regeneração) e temporais (eternidade). Logo, torna-se fundamental pensar sobre o tempo - o que será feito a seguir.

\subsection{Fatias do tempo em Ad Vitam}

Cena 1. Em um sofisticado restaurante clandestino com serviço à la carte, oferecendo pratos com carne animal e seleção de músicas em um jukebox, Odessa (interpretada por Ariane Labed), antagonista da 
trama, comenta para Darius em tom provocador: "Você sabe bem como sentir a passagem do tempo é a única forma de suportar a eternidade".

Cena 2. No Museu Stern, espaço dedicado a expor a história e as conquistas científicas do processo de regeneração, seu público - visivelmente, uma parcela de elevada classe social da sociedade francesa assiste a uma cena inusitada, causadora de repulsa e fascínio na plateia: conectados a tubos respiratórios, jovens sedados surgem em aquários transparentes com líquido, envelhecendo dezenas de anos em minutos, como uma forma de timelapse transmitido ao vivo.

Trata-se de um espetáculo que serve para entreter e ensinar ao exibir de maneira repulsiva e sensacionalista o processo de envelhecimento. Neste ponto, é fundamental realizar um paralelo com determinadas práticas: como os zoológicos; o comércio de escravizados africanos e indígenas - até poucos séculos realizado em praça pública no Brasil; e os espetáculos racistas circenses, explicitados por Sarah Baartman, a Vênus Hotentote (PARKINSON, 2016).

Um dos jovens apresentados no Museu Stern é Christa, que aparece de forma semelhante à águaviva que sua família mantém em aquário no ambiente doméstico. No histórico pessoal da menor, há registro de internação por seus genitores em clínica psiquiátrica após seu "malsucedido" envolvimento no suicídio coletivo organizado pela SAUL - sua alta se deu em virtude da convocação de Darius para auxílio na investigação criminal. De volta ao convívio familiar, seus pais buscam, insistentemente, convencê-la da regeneração, sabendo que Christa é compatível com o tratamento. Para eles, sua insurgência e inconformismo são incômodos e ameaçadores.

Num momento de discussão com os pais, Christa lança a água-viva da casa sobre a mesa de jantar da família. O efeito do gesto é significativo: o animal é o símbolo da imortalidade, e Christa deseja colocar o tempo em xeque.

É enriquecedor pensar sobre sua atitude à luz do entendimento da história da mentalidade, concebida após a Primeira Guerra Mundial a partir de um grupo de historiadores formado por Lucien Febvre e Marc Bloch, Henri Pirenne, Albert Demangeon, Lucien Lévy-Bruhl e Maurice Halbwachs (ADAY, 2019). De fato, essa perspectiva de estudo toma fôlego na segunda metade do século XX, como aponta Barros (2007, p. 13, grifo nosso): 
Essa nova modalidade da História, que tem precursores já na primeira metade do século XX, mas que, rigorosamente, começa a se delinear como um novo espaço de ação para os historiadores na segunda metade do século, propunha-se a enfocar a dimensão da sociedade relacionada ao mundo mental e aos modos de sentir.

Ao dirigir o olhar para o passado, revelam-se impressões, valores culturais e regras de conduta impregnados no imaginário coletivo, reconhecendo-os como componentes da dinâmica social praticados pela sociedade na contemporaneidade. Com isso, tem-se o benefício de obtenção de clareza sobre o entendimento do tempo presente.

Para Phillipe Ariès (2011), a história das mentalidades permite uma compreensão prévia do passado de uma sociedade. A proposta do autor estabelece relação com a visão de Giorgio Agamben (2009, p. 62) a partir da ênfase na importância do passado para a compreensão do presente, pois "contemporâneo é aquele que mantém fixo o olhar no seu tempo, para nele perceber não as luzes, mas o escuro".

No cenário distópico apresentado, a morte é sedutora: vive-se a eternidade e se estabelece como premissa a espetacularização do envelhecimento. As duas cenas descritas apresentam suas personagens como espectadoras do "envelhecer": a garantia da eternidade exige revestir a passagem do tempo de forma simbólica, suscitando a criação de entretenimentos ou a adoção de novas condutas sociais e legais, como - por exemplo - a aprovação do controle de natalidade. Afinal, torna-se oportuno restringir o contingente populacional a fim de não inflar o quadro demográfico, uma vez que se vive mais.

Compreendem-se esses hábitos e vigências correntes da sociedade representada quando se resgata a construção das mentalidades em questão, privilegiando a "estrutura mental" e a "visão de mundo" contemporâneas (ARIÈS, 2011). No caso em estudo, destacam-se a possibilidade da morte iminente após a vivência de uma pandemia, a postergação da maioridade e o veemente desejo pela juventude eterna. Ao recorrer às motivações subjetivas dos indivíduos e suas consequências práticas, podem-se "subtrair ao presente fatias de passado, tornando muito mais delgado o presente, a ponto de transformá-lo em algo transparente". (ARIÈS, 2011, p. 293).

Essa transparência propicia vislumbrar os percursos individuais no tratamento de aspectos subjetivos e na elaboração de projetos de vida pessoais. Convém compreender essa categoria e suas possíveis leituras a partir das trajetórias de algumas das personagens da série. 


\subsection{Projeto de vida em Ad Vitam}

O final de Ad Vitam é emblemático: veem-se Christa e outros jovens embarcando em uma lancha. A tentativa de escape deixada em aberto com o encerramento da trama é mais do que uma aventura inclusive, com possíveis mortes -; é a condição por parte desses jovens de lançarem-se diante da possibilidade de viver autonomamente.

Eles buscam desviar-se das limitações impostas à sua existência: recusam a restrição da natalidade - recém-aprovada em plebiscito por $88 \%$ da população - ou uma eventual internação manicomial para tratamento daqueles que se opõem ao sistema social, como ocorreu com a própria Christa.

A sequência final é coroada com uma cena singular. Já embarcados e ao mar, emprega-se um enquadramento com quebra da quarta parede: Christa dirige o olhar ao espectador, revelando um misto de alegria, esperança e expectativa. Nessa rota, há um projeto de vida, um desvio em curso, uma abertura para novos relacionamentos e interações.

A atenção a práticas de socialização é um exercício relevante para a interface das ciências humanas e sociais. Destaca-se, por exemplo, a Escola de Chicago, no início do século XX, emergindo diante de grandes alterações na sociedade americana - questões e desafios atrelados à cidade moderna. $\mathrm{O}$ quadro social local redesenhava-se diante da industrialização e da urbanização; da afluência de imigrantes de outras culturas; da dissolução da estrutura política e econômica descentralizada, aliada a mudanças econômicas, além do surgimento de uma nova classe média profissional.

O tratamento analítico dado a essas transformações sociais é passível de projeção e diálogo com o cenário distópico de $A d$ Vitam, uma vez que se baseiam em revisões do problema da ação propriamente dita e da consciência humana (COULON, 1995; BECKER, 1996; VALLADARES, 2005).

Um dos principais disseminadores dos referenciais da Escola de Chicago no Brasil foi Gilberto Velho (1945-2012). O antropólogo explorou a tradição interacionista a partir das contribuições de Erving Goffman (1922-1982) sobre estigma e representação social, e de Howard S. Becker (1928-) sobre desvio e rotulação. Velho (2002, p. 13, grifos do autor) descreve esse contexto de produção de conhecimento a partir da confluência de campos disciplinares: 
A presença de Goffman e Becker valorizou a contribuição da ciência social norte-americana para a temática indivíduo e sociedade, através da Escola de Chicago e, especificamente da linha interacionista. Ambos não viam como barreiras os limites acadêmicos entre sociologia e antropologia. Atravessavam-nos e consideravam-nos desnecessários ou até como fonte de mal-entendidos. Convém lembrar que na Universidade de Chicago, durante quase 40 anos, até 1929, havia um único departamento com antropólogos e sociólogos.

A interação social entre sujeitos e as situações provenientes de exercícios de sociabilidade a partir do individual com o coletivo trazem novas significações sobre fatos e ocorrências compartilhadas a partir da troca de opiniões manifestas, interpretações (pessoais e comunitárias), valores convencionais e interditos, entre outros comportamentos e ideias.

Velho (2002; 2008) absorve as premissas de Chicago, desses pensadores, além de outros, para dirigir seu olhar ao indivíduo e seu itinerário pessoal. O conceito de "projeto" (SCHUTZ, 1979; VELHO, 2008), por exemplo, deriva do reconhecimento de que os sujeitos escolhem ou podem exercer escolhas. Ao estabelecer "o que se quer e o que se pretende", o sujeito constrói um plano e formula estratégias relacionadas à sua história de vida. Diz Velho (2008, p. 28, grifo do autor):

Os projetos são elaborados e construídos em função de experiências socioculturais, de um código, de vivências e interações interpretadas. Mas como se identifica um projeto? É claro que se podem deduzir as razões da conduta dos indivíduos, interpretar suas ações e especular sobre suas motivações. O problema é saber se o resultado obtido corresponde ao que os indivíduos, em pauta, realmente projetaram.

Claramente, um projeto pode ser reconfigurado diante da realidade que se delineia, sendo conveniente recorrer à discursividade do sujeito como forma de aferição e mapeamento de suas expectativas pessoais. O projeto articula-se ainda diretamente com a trajetória de vida do sujeito e enseja, complementarmente, a compreensão sobre os "contextos individualizadores" e o "sistema de relevância" vivenciado pelos indivíduos em uma sociedade. O contexto reconhece o sujeito como uma unidade significativa - e em torno dele se forma um sistema de relevância.

Para Velho (2008), o contexto privilegia a dimensão cultural e simbólica presente em todos os níveis da vida social. Constitui-se, portanto, como uma rede de componentes que travam relações significativas. Já o sistema de relevância compreende um campo de domínios validados socialmente por meio do qual um determinado grupo social ordena seu mundo e elabora seu estilo de vida: "em função dessas relevâncias, os indivíduos desse grupo social armam suas estratégias de vida, fazem opções, estabelecem projetos." (VELHO, 2008, p. 90). 
Em Ad Vitam, o contexto legitima uma longevidade que se blinda com a regeneração, uma vitalidade artificial, além da tangência com a morte, que se preserva excitante e sedutora - dela, melhor se esquivar. A distopia narrativa desenha um cenário controlador e asfixiante, institucionalizado por meio de um sistema de relevância articulado e integrado à sociedade: a eternidade para grande parcela desse coletivo é um continuum plano, destituído de disrupções.

Na narrativa, o Museu Stern inclusive obtém de modo ilegal os dados dos jovens vinculados à Fundação Amanhã - instituição mantida por um grupo contrário à imposição social de defesa da vida eterna. O "suposto" suicídio coletivo na praia corresponde, portanto, a uma ação criminal de assassinato dos jovens orquestrada pelo Museu a fim de eliminar aqueles considerados "inúteis ao sistema", os incompatíveis com o procedimento de regeneração.

Esse episódio dialoga, portanto, com a noção de psicopolítica dos dados (HAN, 2018, p. 93, grifos do autor), que se vale precisamente de técnicas de big data e micro-targeting para a construção de um conhecimento movido a dados, números e outros registros:

A memória digital se constitui de momentos presentes indiferentes ou, por assim dizer, de momentos zumbis. Falta-lhe esse horizonte temporal estendido que constitui a temporalidade dos viventes. Com isso, a vida digital perde sua vitalidade. A temporalidade do digital é a dos mortos-vivos.

Por outro lado, tal temporalidade permite o acesso a uma espécie de inconsciente digital, cuja memória, diferente da humana - narrativa -, é acumulativa, "uma simples adição de eventos ou informações" (HAN, 2018, p. 92). A presença do Museu Stern na série operacionaliza essa dinâmica pósmoderna e se dá, ironicamente, de forma ambivalente: apropria-se de dados "sem vida" a fim de garantir a eternidade dos viventes. Sua conduta política e organizacional a legitima enquanto uma instituição não apenas imersa, como também totalmente interessada na manutenção de uma mentalidade amparada pela psicopolítica dos dados.

Ações de enfrentamento e insurgência são esperadas diante de um cenário como o descrito. Eventuais fraturas e disjunções podem ocorrer, principalmente, quando surgem dinâmicas de individualização. Sobre esse processo e acerca da emergência de comportamentos desviantes, salienta Velho (2008, p. 26, grifos do autor):

Em toda sociedade existe, em princípio, a possibilidade da individualização. Em algumas será mais valorizada e incentivada do que em outras. De qualquer forma o processo de individualização não se dá fora de normas 
e padrões por mais que a liberdade individual possa ser valorizada. Quando vai de encontro às fronteiras simbólicas de determinado universo cultural - ou as ultrapassa -, ter-se-á então, provavelmente, uma situação de desvio com acusações e, em certos casos, estigmatização. [...] Logo, a possibilidade da existência de projetos individuais está vinculada a como, em contextos socioculturais específicos, se lida com a ambiguidade fragmentação-totalização. [...] Quando há ação com algum objetivo predeterminado ter-se-á o projeto.

A relação entre projeto individual e desvio ganha projeção quando se reconhece o estabelecimento de ações de enfrentamento direto, como as práticas suicidas (tal como a formação da SAUL) ou a construção de outras rotas - tais quais, por exemplo, as traçadas entre os jovens que participam da Fundação Amanhã, sem projeto de futuro pré-definido, ou mesmo por aqueles que desejam envelhecer naturalmente.

Christa adota esta última alternativa, mas opta por aventurar-se, a fim de ingressar em novos contextos e sistemas de relevância - longe de distopias. Seu processo de individualização desenha-se com a partida do solo pátrio, acompanhada da busca por cenários sociais em que as margens de escolha sejam mais amplas e libertárias para o exercício de suas realizações.

\section{Considerações finais}

De acordo com a sabedoria popular, "a única certeza que se tem na vida é a morte". Mesmo assim, é antigo o desejo dos seres humanos de estraçalhar tal conviç̧ão, alcançar a imortalidade, desafiar a morte. Na cultura ocidental, multiplicam-se as narrativas sobre o tema: fontes da juventude, elixires mágicos, voltas no tempo.

No Brasil e no mundo, é cada vez mais expressiva a busca por procedimentos cirúrgicos estéticos para rejuvenescer, harmonizar e "levantar" partes do corpo, suavizar expressões faciais e suas marcas, reduzir rastros e efeitos desenhados pelo tempo (SBCP, 2018). Simultâneo a esse fenômeno, é notório o crescente número de quadros relacionados ao sofrimento psíquico, potencializados pela pandemia do COVID-19 (GUTERRES, 2020).

Imersos em um cenário distópico com contexto restritivo e sistema de relevância engessado, dedicar-se à elaboração de projetos de vida e ações desviantes é sopro de estímulo. As novas atividades sociais e condutas pessoais serão, porventura, criadas, testadas e reelaboradas diante de um eventual 
insucesso ou da necessidade de readequação. Essa ciranda mantém-se viva com sujeitos motivados a constituir e reconfigurar uma resposta própria.

Neste sentido, Ad Vitam descortina interpretações sobre o agir humano e aposta no comportamento desviante como uma manobra original capaz de ultrapassar o cenário distópico, refutando a fantasmagoria que the é inerente e revestindo o futuro com um novo imaginário - mais convidativo, inspirador e humano. Com isso, amplia-se a perspectiva de discussão e projeção sobre as práticas coletivas manifestas em sociedade, seu potencial de invenção (e contravenção) e a sua efetiva força motriz: o próprio sujeito.

\section{Breno da Silva Carvalho}

ORCID: https://orcid.org/0000-0003-3196-2328 Universidade Federal do Rio Grande do Norte, Departamento de Comunicação, Natal (RN), Brasil Doutor em Antropologia pela UFBA E-mail:brenosc@uol.com.br

Raquel Assunção Oliveira

ORCID: https://orcid.org/0000-0001-9876-7151 Universidade Federal do Rio Grande do Norte, Departamento de Comunicação, Natal (RN), Brasil Mestre em Comunicação pela UFRN E-mail: assuncaoraqueloliveira@gmail.com

Recebido em: 15 de março de 2021.

Aprovado em: 1 de abril de 2021. 


\section{Referências}

ADAY, Yuliedys Ruiz. Acercamiento a la historia de las mentalidades. Uisrael, Revista Científica, v. 6, n. 2, mai./ago. 2019.

AD VITAM. Direção: Thomas Cailley e Manuel Schapira. Produção: Katia Raïs (Kelija Productions). França: Arte. 2018 - presente (6 episódios). Título original: Ad Vitam.

AGAMBEN, Giorgio. O que é o contemporâneo? e outros ensaios. Chapecó, SC: Argos, 2009.

ALMEIDA, Marco Antônio de. Sangue, suor \& tiros: a narrativa policial na literatura e cinema brasileiros. 2002. Tese (Doutorado em Ciências Sociais). Instituto de Filosofia e Ciências Humanas - Universidade Estadual de Campinas, São Paulo, 2002.

. O cinema policial no Brasil: entre o entretenimento e a crítica social. In: Cadernos de Ciências Humanas - Especiaria, v. 10, n.17, jan./jun., 2007, p. 137-173. Disponível em: https://periodicos.uesc.br/index.php/especiaria/article/view/864. Acesso em: 19 mai. 2021.

ALMEIDA, Rogério de. Cinema, educação e imaginários contemporâneos: estudos hermenêuticos sobre distopia, niilismo e afirmação nos filmes $\mathrm{O}$ som ao redor, O cavalo de Turim e Sono de inverno. Educação e Pesquisa, São Paulo, v. 44, e175009, mar. 2018. Disponível em: http://www.scielo.br/scielo.php?script=sci_arttext\&pid=S1517-97022018000100441\&lng=pt\&nrm=iso.

Acesso em: 19 mai. 2021.

ARIÈS, Phillipe. A história das mentalidades. In: NOVAIS, Fernando Antônio; SILVA, Rogério Forastieri da (Orgs.). Nova história em perspectiva. V. 1. São Paulo: Cosac Naify, 2011, p. 268-295.

BARROS, José D’Assunção. História, imaginário e mentalidades: delineamentos possíveis. Conexão Comunicação e Cultura, Caxias do Sul, v. 6, n. 11, jan./jun. 2007.

BECKER, Howard S. A Escola de Chicago. Mana, Estudos de Antropologia Social, Rio de Janeiro, v. 2, n. 2, p. 177-188, out. 1996.

. Outsiders: estudos de sociologia do desvio. Rio de Janeiro: Zahar, 2008.

BERGER, Peter L. Perspectivas sociológicas: uma visão humanística. Tradução de Donaldson $M$. Garschagen. 5. ed. Petrópolis: Vozes, 1980. Antropologia, 1.

BERGER, Peter L.; LUCKMANN, Thomas. A construção social da realidade: tratado de sociologia do conhecimento. Tradução de Floriano de Souza Fernandes. 4. ed. Petrópolis, RJ: Vozes, 1978. Antropologia, 5.

CAILLEY, Thomar. Ad Vitam, la série SF et policière événement d'Arte se dévoile. AlloCiné, Levallois-Perret, 10 fev. 2018. Entrevista concedida a Brigitte Baronnet. Disponível em: https://www.allocine.fr/diaporamas/series/diaporama-18670384/. Acesso em: 05 fev. 2021.

COULON, Alain. A Escola de Chicago. Campinas: Papirus, 1995. 
FEATHERSTONE, Mike. Cultura de consumo e pós-modernismo. São Paulo: Nobel, 1995.

FOUCAULT, Michel. Poder-corpo. In: . Microfísica do Poder. São Paulo: Paz e Terra, 2021, p. 234 243.

. Vigiar e punir: nascimento da prisão. Rio de Janeiro: Vozes, 2014.

FRÚGOLI Jr., Heitor. Sociabilidade urbana. Rio de Janeiro: Jorge Zahar, 2007. (Passo-a-passo, n. 80).

GARDNER, Chris; MCCLINTOCK, Pamela. 'Contagion' Hits Top 10 on iTunes Movie Chart Amid Coronavirus Outbreak. The Hollywood Reporter, 2020. Disponível em: https://www.hollywoodreporter.com/ramblingreporter/contagion-hits-top-10-itunes-movie-chart-coronavirus-outbreak-1274163. Acesso em: 05 fev. 2021.

GIDDENS, Anthony. A constituição da sociedade. Tradução de Álvaro Cabral. São Paulo: Martins Fontes, 1989. (Coleção ensino superior).

GOFFMAN, Erving. A representação do eu na vida cotidiana. Petrópolis/Rio de Janeiro: Vozes, 1975.

GOMES, Wilson. La poética del cine y la cuestión del metodo en el análisis fílmico. Revista Significação (UTP), Curitiba, v. 21, n. 1, p. 85-106, 2004.

GUTERRES, António. Mental health services are an essential part of all government responses to COVID19. United Nations, COVID-19 Response, 13 mai. 2020. Disponível em: https://www.un.org/en/coronavirus/mental-health-services-are-essential-part-all-government-responsescovid-19. Acesso em: 07 mar. 2021.

HAN, Byung-Chul. Psicopolítica: o neoliberalismo e as novas técnicas de poder. Belo Horizonte: Âyiné, 2018.

Sociedade do cansaço. Petrópolis, RJ: Vozes, 2017.

MORIN, Edgar. O cinema ou o homem imaginário: ensaio de antropologia sociológica. São Paulo: Realizações, 2014.

PARKINSON, Justin. Sarah Baartman: a chocante história da africana que virou atração de circo. BBC News Brasil, São Paulo, 112 jan. 2016.2 Disponível em: https://www.bbc.com/portuguese/noticias/2016/01/160110_mulher_circo_africa_lab?ocid=socialflow_fa cebook. Acesso em: 11 mar. 2021.

PENAFRIA, Manuela. Análise de filmes: conceitos e metodologia(s). Anais do VI Congresso SOPCOM. Abr., 2009. Disponível em: http://www.bocc.ubi.pt/pag/bocc-penafria-analise.pdf. Acesso em: 05 mar. 2021.

ROSA, Jorge Pereira. Ad Vitam: a série francesa "para a eternidade". C7nema, 05 nov. 2018. Disponível em: https://c7nema.net/artigos/item/49530-ad-vitam-a-serie-francesa-para-a-eternidade.html. Acesso em: 05 fev. 2021. 
SBPC. Censo 2018: análise comparativa das pesquisas 2014, 2016 e 2018. Sociedade Brasileira de Cirurgia Plástica. Disponível em: $<$ http://www2.cirurgiaplastica.org.br/wpcontent/uploads/2019/08/Apresentac\%CC\%A7a\%CC\%83o-Censo-2018 V3.pdf>. Acesso em: 07 mar. 2021.

SCHUTZ, Alfred. Fenomenologia e relações sociais. Rio de Janeiro: Zahar, 1979.

VALLADARES, Lícia do Prado (Org.). A Escola de Chicago. Impacto de uma tradição no Brasil e na França. Belo Horizonte/Rio de Janeiro: Editora UFMG/IUPERJ, 2005

VELHO, Gilberto. Becker, Goffman e a antropologia no Brasil. Sociologia, problemas e práticas, n. 38, p. 917, 2002.

. Individualismo e cultura: notas para uma antropologia da sociedade contemporânea. Rio de Janeiro: Jorge Zahar, 2008.

WHO. Preventing suicide: a global imperative. World Health Organization. Disponível em: <https://apps.who.int/iris/bitstream/handle/10665/131056/9789241564779 eng.pdf;jsessionid=0A067E8 OF123E608CEA09A70418D3955? sequence=1>. Acesso em: 07 mar. 2021.

\section{Resumo}

Debruçando-se sobre o universo criado por Sébastien Mounier na série Ad Vitam (2018), dirigida por Thomas Cailley e Manuel Schapira, tem-se a oportunidade de debater sobre a perpetuidade da vida e as motivações subjetivas individuais à luz de referenciais socioantropológicos e comunicacionais contemporâneos. Ao considerar a vivência em ambiente distópico, seus desafios e insurgências para a sociedade e o coletivo, o presente artigo tem como objetivo analisar questões acerca dos efeitos da saúde, do tempo e da construção de projetos de vida a partir do enredamento narrativo da série.

Palavras-chave: Distopia. Tempo. Projeto de vida. Audiovisual. Narrativas contemporâneas. 


\section{Abstract}

Looking at the universe created by Sébastien Mounier in the series Ad Vitam (2018), directed by Thomas Cailley and Manuel Schapira, we have the opportunity to debate about the perpetuity of life and individual subjective motivations in the light of contemporary socio-anthropological referentials. When considering living in a dystopian environment, its challenges and insurgencies for society and the collective, this article aims to analyze questions about the effects of health, time and the construction of life projects based on the narrative of the series.

Keywords: Dystopia. Time. Life project. Cinema. Contemporary narratives.

\section{Resumen}

Mirando el universo creado por Sébastien Mounier en la serie Ad Vitam (2018), dirigida por Thomas Cailley y Manuel Schapira, tenemos la oportunidad de debatir sobre la perpetuidad de la vida y las motivaciones subjetivas individuales a la luz de las referencias socioantropológicas y comunicacionales contemporáneas. Al considerar vivir en un entorno distópico, sus desafíos e insurgencias para la sociedad y el colectivo, este artículo tiene como objetivo analizar interrogantes sobre los efectos de la salud, del tiempo y la construcción de proyectos de vida a partir del entrelazamiento narrativo de la serie.

Palavras clave: Distopía. Tiempo. Proyecto de vida. Audiovisual. Narrativas contemporáneas.

Este artigo é publicado em acesso aberto (Open Access) sob a licença Creative Commons Attribution Non-Commercial (CC-BY-NC 4.0), que permite que outros remixem, adaptem e criem a partir do seu trabalho para fins não comerciais, e embora os novos trabalhos tenham de lhe atribuir o devido crédito e não possam ser usados para fins comerciais, os usuários não têm de licenciar esses trabalhos derivados sob os mesmos termos. 